\title{
Acute Moderate Hypoxia Reduces One-Legged Cycling Performance Despite Compensatory Increase in Peak Cardiac Output: A Pilot Study
}

\author{
Hannes Gatterer 1,*(iD, Verena Menz ${ }^{2}$ and Martin Burtscher ${ }^{2,3}{ }^{(D)}$ \\ 1 Institute of Mountain Emergency Medicine, Eurac Research, 39100 Bolzano, Italy \\ 2 Department of Sport Science, University of Innsbruck, 6020 Innsbruck, Austria; \\ verena.menz@uibk.ac.at (V.M.); Martin.Burtscher@uibk.ac.at (M.B.) \\ 3 Austrian Society for High Altitude and Mountain Medicine, 6020 Innsbruck, Austria \\ * Correspondence: hannes.gatterer@eurac.edu
}

check for updates

Citation: Gatterer, H.; Menz, V.; Burtscher, M. Acute Moderate Hypoxia Reduces One-Legged Cycling Performance Despite Compensatory Increase in Peak Cardiac Output: A Pilot Study. Int. J. Environ. Res. Public Health 2021, 18, 3732. https://doi.org/10.3390/ ijerph18073732

Academic Editors: Zbigniew Jastrzębski, Guillermo Felipe López Sánchez, Łukasz Radzimiński and Maria Skalska

Received: 1 March 2021

Accepted: 30 March 2021

Published: 2 April 2021

Publisher's Note: MDPI stays neutral with regard to jurisdictional claims in published maps and institutional affiliations.

Copyright: (c) 2021 by the authors. Licensee MDPI, Basel, Switzerland. This article is an open access article distributed under the terms and conditions of the Creative Commons Attribution (CC BY) license (https:// creativecommons.org/licenses/by/ $4.0 /)$.

\begin{abstract}
In severe hypoxia, single-leg peak oxygen uptake $\left(\mathrm{VO}_{2 \text { peak }}\right)$ is reduced mainly due to the inability to increase cardiac output (CO). Whether moderate altitude allows $\mathrm{CO}$ to increase during single-leg cycling, thereby restoring $\mathrm{VO}_{2 \text { peak, }}$, has not been extensively investigated. Five healthy subjects performed an incremental, maximal, two-legged cycle ergometer test, and on separate days a maximal incremental one-leg cycling test in normoxia and in moderate hypoxia (fraction of inspired oxygen $\left.\left(\mathrm{FiO}_{2}\right)=15 \%\right)$. Oxygen uptake, heart rate, blood pressure responses, power output, and CO (PhysioFlow) were measured during all tests. Moderate hypoxia lowered single-leg peak power output $(154 \pm 31$ vs. $128 \pm 26$ watts, $p=0.03)$ and oxygen uptake $\left(\mathrm{VO}_{2}\right)(36.8 \pm 6.6$ vs. $33.9 \pm 6.9 \mathrm{~mL} / \mathrm{min} / \mathrm{kg}, p=0.04)$, despite higher peak $\mathrm{CO}(16.83 \pm 3.10 \mathrm{vs} .18 .96 \pm 3.59 \mathrm{~L} / \mathrm{min}$, $p=0.04)$ and systemic oxygen $\left(\mathrm{O}_{2}\right)$ delivery $(3.37 \pm 0.84$ vs. $3.47 \pm 0.89 \mathrm{~L} / \mathrm{min}, p=0.04)$ in hypoxia compared to normoxia. Arterial-venous $\mathrm{O}_{2}$ difference $\left(\mathrm{a}-\mathrm{vDO}_{2}\right)$ was lower in hypoxia $(137 \pm 21$ vs. $112 \pm 19 \mathrm{~mL} / 1, p=0.03)$. The increases in peak $\mathrm{CO}$ from normoxia to hypoxia were negatively correlated with changes in mean arterial pressure (MABP) $(p<0.05)$. These preliminary data indicate that the rise in $\mathrm{CO}$ was not sufficient to prevent single-leg performance loss at moderate altitude and that enhanced baroreceptor activity might limit $\mathrm{CO}$ increases in acute hypoxia, likely by reducing sympathetic activation. Since the systemic $\mathrm{O}_{2}$ delivery was enhanced and the calculated a- $\mathrm{vDO}_{2}$ reduced in moderate hypoxia, a potential diffusion limitation cannot be excluded.
\end{abstract}

Keywords: moderate altitude; small muscle mass; exercise performance; single-leg exercise

\section{Introduction}

During exercise involving a large muscle mass (e.g., two-leg cycling), maximal oxygen uptake $\left(\mathrm{VO}_{2 \max }\right)$ and exercise performance are mainly limited by cardiac output $(\mathrm{CO})$ and thus the ability to deliver oxygen $\left(\mathrm{O}_{2}\right)$ to the working muscles. Besides $\mathrm{CO}$ and the oxygen content of the arterial blood $\left(\mathrm{CaO}_{2}\right)$, blood flow to and $\mathrm{O}_{2}$ extraction of contracting skeletal muscles are also determinants of $\mathrm{VO}_{2 \max }$ [1-4]. On the contrary, when exercising with a small muscle mass (e.g., single-leg cycling, arm or knee-extensor exercise), $\mathrm{CO}$ is not considered the limiting factor for $\mathrm{VO}_{2 m a x}$ attainment, since maximal $\mathrm{CO}$ values are generally not achieved [5-7].

In acute hypoxia (e.g., high altitude) conditions, $\mathrm{CaO}_{2}$ and arterial $\mathrm{O}_{2}$ partial pressure $\left(\mathrm{PaO}_{2}\right)$, which constitute the driving pressure behind $\mathrm{O}_{2}$ diffusion [8], are reduced. Thus, if not compensated by an increased $\mathrm{CO}$ and/or $\mathrm{O}_{2}$ extraction, aerobic capacity may be impaired, even when exercising with a small muscle mass. Indeed, in circumstances of severe hypoxia, similar or reduced $\mathrm{CO}$ and leg blood flow during single-leg exercise have been observed compared to normoxic conditions, which translates into reduced leg $\mathrm{O}_{2}$ delivery [1,9] and impaired $\mathrm{VO}_{2 \mathrm{max}}$. Thus, $\mathrm{CO}$, despite ample functional reserve, seems not 
to be sufficiently increased to compensate for the reduced $\mathrm{CaO}_{2}$ in acute severe hypoxia [1]. In this regard, it is important to mention that increasing $\mathrm{CO}$ would not only increase leg $\mathrm{O}_{2}$ delivery, but also shorten capillary transit time and may thus limit time for $\mathrm{O}_{2}$ diffusion $[5,7,10] . \mathrm{O}_{2}$ extraction demonstrates a marked plateau in hypoxia and maximal values are similar in normoxia, indicating that muscle diffusive capacity plays a role in the $\mathrm{VO}_{2 \max }$ reduction at altitude $[9,11]$. The magnitude of this diffusion limitation is, however, controversially discussed $[8,12,13]$. Due to restoration of $\mathrm{CaO}_{2}$ during altitude acclimatization and single-leg $\mathrm{VO}_{2 \text { peak }}, \mathrm{O}_{2}$ delivery, and not diffusional limitation at the muscle level, has been suggested as the primary reason for the $\mathrm{VO}_{2 \text { peak }}$ reduction in acute hypoxia [1].

It needs to be considered that the study design, the actual muscle mass involved, as well as the participant's fitness level may influence the physiological responses during exercise performed in hypoxia $[6,9,12]$. Rowell et al. [5], for instance, investigated untrained participants performing single-leg knee extension exercise at a peak workload stage, which was determined by pre-testing. Using this study design, $\mathrm{CO}$ and muscle blood flow reached higher values in severe hypoxia compared to normoxia [5], which is in contrast to the findings reported for well-trained athletes performing graded exercise tests to exhaustion $[1,9,11]$.

Besides exercise setting and physical fitness levels of participants, the severity of hypoxia (altitude level) may also play a critical role when assessing factors limiting $\mathrm{VO}_{2 \text { peak }}$ of small muscle mass in hypoxia [14]. The aforementioned studies performed exercise testing in severe hypoxia $\left(\mathrm{FiO}_{2}<0.12\right.$ corresponding to altitude levels $>4000 \mathrm{~m}$ ), with a large impact on $\mathrm{CaO}_{2}$ and $\mathrm{O}_{2}$ delivery to the myocardium, respiratory muscles, and the central nervous system (CNS) [1]. Low brain $\mathrm{O}_{2}$ delivery thus could have caused a cardioinhibitory reflex, eventually preventing a compensatory increase in CO [1]. Interestingly, to the best of our knowledge, only limited information is available on whether similar effects may occur in moderate hypoxia (i.e., $\mathrm{FiO}_{2}=15 \%$ ), where $\mathrm{PaO}_{2}$ and $\mathrm{CaO}_{2}$ are less affected. Physical activity involving small muscle mass is commonly performed at moderate altitudes, e.g., by workers, tourists, and athletes. Thus, insights on a potential loss of small muscle performance and related mechanisms when acutely exposed to rather moderate altitude is of scientific, as well as clinical/practical, relevance.

To investigate whether moderate hypoxia allows $\mathrm{CO}$ to increase during exercise with a small muscle mass, eventually restoring normoxic $\mathrm{O}_{2}$ delivery and $\mathrm{VO}_{2 \text { peak }}$, we evaluated hemodynamic and performance parameters during maximal single-leg exercise in normoxia and at a $\mathrm{FiO}_{2}$ of $15 \%$. Even though muscle $\mathrm{O}_{2}$ diffusion might be affected by a reduced transit time, we hypothesized that at a moderate altitude, small muscle performance would be preserved by compensatory increases in $\mathrm{CO}$ and oxygen delivery.

\section{Materials and Methods}

\subsection{Participants}

Five healthy and fit subjects (three males, age: $41 \pm 13$ years; two females, age: $45 \pm 7$ years) volunteered to participate in this pilot study. Inclusion criteria were age between 25 and 55 years, no recent health problems (checked by routine medical examination) and no exposures to hypoxia or altitude over $1500 \mathrm{~m}$ at least 4 weeks before exercise testing. All participants regularly participated (at least $1 \mathrm{~h}$ per day on 3 days per week) in various sports (e.g., running, cycling, swimming) and did not complete specific cycling training prior to their participation. Their baseline characteristics are shown in Table 1. Subjects gave their informed consent prior to their inclusion in the study, which has been performed in accordance with the ethical standards laid down in the Declaration of Helsinki. The study was approved by the local ethics review board (University of Innsbruck, Department of Sport Science, ZI.014/2010). 
Table 1. Baseline characteristics of the participants $(n=5)$.

\begin{tabular}{cc}
\hline Variables & Mean \pm SD \\
\hline Age (years) & $42.6 \pm 10.2$ \\
Weight $(\mathrm{kg})$ & $62.8 \pm 10.6$ \\
Height $(\mathrm{cm})$ & $175.6 \pm 5.7$ \\
$\mathrm{BMI}\left(\mathrm{kg} / \mathrm{m}^{2}\right)$ & $20.3 \pm 2.5$ \\
$\mathrm{HR}_{\max }\left(\mathrm{b} / \mathrm{min}^{2}\right)$ & $180.6 \pm 2.7$ \\
$\mathrm{P}_{\max }(\mathrm{W} / \mathrm{kg})$ & $4.5 \pm 0.7$ \\
$\mathrm{VO}_{2 \max }(\mathrm{ml} / \mathrm{min} / \mathrm{kg})$ & $49.1 \pm 7.0$ \\
Lamax $(\mathrm{mmol} / \mathrm{l})$ & $10.6 \pm 1.6$ \\
Sport practice $(\mathrm{h} /$ week $)$ & $6.0 \pm 0.8$ \\
\hline Body mass index, BMI; maximal heart rate, HR $\mathrm{HR}_{\max ; \text { maximal lactate concentration, Lamax; maximal power }}$ \\
output, $\mathrm{P}_{\text {max }}$ maximal oxygen uptake, $\mathrm{VO}_{2 \text { max }}$. Maximal values represent values during maximal two-legged \\
cycling exercise.
\end{tabular}

\subsection{Protocol}

Participants visited the laboratory on three separate days: day 1 for routine medical examination, maximal (two-legged) cycle ergometer testing, and familiarization with oneleg cycling; days 2 and 3 for maximal one-legged (dominant leg) cycling tests in normoxia and hypoxia (Figure 1).

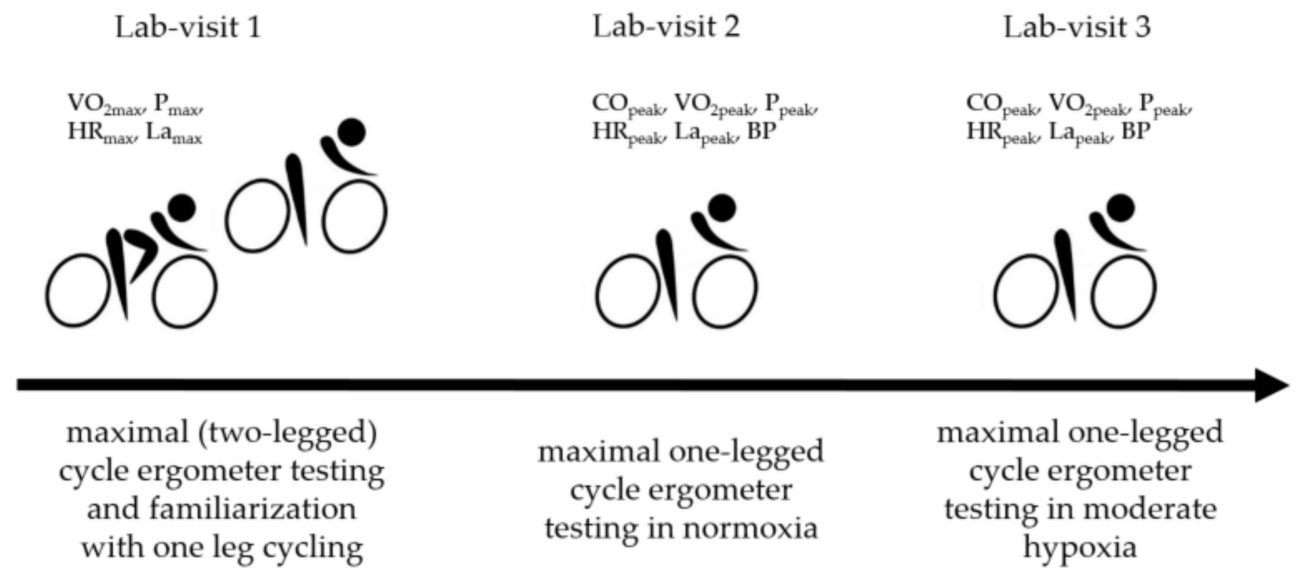

Figure 1. Experimental design. Blood pressure, BP; cardiac output, $\mathrm{CO}$; heart rate, HR; lactate concentration, La; oxygen uptake, $\mathrm{VO}_{2}$; power output, $\mathrm{P}$.

\subsection{One-Legged Exercise Tests}

The one-legged cycle ergometer tests were conducted on an electrodynamically braked cycle ergometer (Excalibur Sport, Lode, the Netherlands). Both trials were performed in the late morning on separate days after a light breakfast at least $2 \mathrm{~h}$ prior to the test and a 10 min warm-up period (two-legged cycling at 40 watts). The handlebar and the saddle of the cycle ergometer were individually adjusted and remained the same in both trials. Resting measurements were performed in a sitting position $(10 \mathrm{~min})$ on the cycle ergometer. After this, the test started with a workload of 20 watts, which was increased by 20 watts every $2 \mathrm{~min}$ until the subject was unable to maintain a pedaling frequency of $30 \mathrm{rpm}$. The first test was performed in normoxia $\left(\mathrm{FiO}_{2}=20.9 \%\right)$ and the second in hypoxia $\left(\mathrm{FiO}_{2}=15 \%\right)$. Subjects were blinded to the applied $\mathrm{FiO}_{2}$. Hypoxic air was delivered by the Hypoxico Altitude Generator (Hypoxico Europe $\mathrm{GmbH}$ ) via a rigid mouthpiece connected to a " $\mathrm{Y}$ " system fixation with a double valve ensuring separate pathways between inspired and expired flow. The same valve system was applied during the normoxia setting.

\subsection{Measurements and Calculation}

Expired gases were analyzed for the assessment of peak oxygen uptake $\left(\mathrm{VO}_{2 \text { peak }}\right)$ by a gas analyzer (Oxycon Alpha, Jaeger, Germany); 15 s averages of peak values were 
taken for analysis. Peripheral oxygen saturation $\left(\mathrm{SpO}_{2}\right)$ was continuously measured by finger pulse oximetry (Nonin, Sanesco, Austria). Blood was taken from the hyperemized earlobe at rest and shortly before finishing the exercise test for determination of $\mathrm{PaO}_{2}$ and hemoglobin concentration (ABL 80 Flex CO-OX OSM, Radiometer, Kopenhagen, Denmark). Lactate concentration (La) was determined at rest before starting the exercise test and $3 \mathrm{~min}$ after test termination (Biosen C-line, EKF diagnostic, Barleben, Germany). For continuous measurement of hemodynamic parameters (heart rate (HR), stroke volume (SV), CO, and total peripheral resistance (TPR)), the non-invasive impedance cardiograph PhysioFlow (Manatec biomedical, Poissy, France) was applied. Six electrodes were properly placed on the neck and chest, according to the manufacturer's instructions. Arterial blood pressure (BP) was measured at rest (sitting on the cycle ergometer) for calibration of the PhysioFlow before each exercise test and at the end of each stage. The signal quality and stability were checked over the entire test period.

Arterial-venous $\mathrm{O}_{2}$ difference $\left(\mathrm{a}-\mathrm{vDO}_{2}, \mathrm{CaO}_{2}-\mathrm{CvO}_{2}\right)$ was calculated using the Fick equation a- $\mathrm{vDO}_{2}=\mathrm{VO}_{2} / \mathrm{CO}$ [15]. Arterial oxygen content $\left(\mathrm{CaO}_{2}\right)$ was calculated as: $\left(\mathrm{Hb} \times 1.34 \times \mathrm{SaO}_{2}\right)+\left(\mathrm{PaO}_{2} \times 0.003\right)$, and systemic $\mathrm{O}_{2}$ delivery as: $\mathrm{CO} \times \mathrm{CaO}_{2}$. Mean arterial blood pressure (MABP) was calculated as: $1 / 3$ (systolic - diastolic) + diastolic BP, and total peripheral resistance (TPR) as: $\mathrm{MABP} / \mathrm{CO}$.

\subsection{Statistics}

Data are presented as mean values ( \pm standard deviation, SD). Wilcoxon signed-rank tests were used to compare means recorded in normoxia and hypoxia. Spearman correlation analyses were performed to test associations between two variables. $p$-values $<0.05$ are considered to indicate statistical significance.

\section{Results}

Resting $\mathrm{SpO}_{2}$ values were higher in normoxia compared to hypoxia, whereas a lower resting HR was observed in normoxia (Table 2).

Table 2. Resting (sitting on the cycle ergometer) values of the normoxia and hypoxia sessions.

\begin{tabular}{cccc}
\hline Variables & Normoxia & Hypoxia & $p$-Value \\
\hline $\mathrm{HR}(\mathrm{b} / \mathrm{min})$ & $59.4 \pm 4.6$ & $64.4 \pm 4.6$ & 0.03 \\
$\mathrm{MABP}(\mathrm{mmHg})$ & $92.2 \pm 3.9$ & $89.7 \pm 6.6$ & 0.43 \\
$\mathrm{SV}(\mathrm{mL})$ & $78.0 \pm 5.8$ & $73.6 \pm 7.8$ & 0.18 \\
$\mathrm{CO}(\mathrm{L} / \mathrm{min})$ & $4.63 \pm 0.46$ & $4.72 \pm 0.33$ & 0.69 \\
$\mathrm{SpO}_{2}(\%)$ & $96.5 \pm 1.2$ & $91.4 \pm 1.1$ & 0.04 \\
$\mathrm{CaO}_{2}(\mathrm{~mL} / \mathrm{L})$ & $190.2 \pm 34.6$ & $178.3 \pm 25.3$ & 0.14 \\
Systemic $\mathrm{O}_{2}$ delivery $(\mathrm{L} / \mathrm{min})$ & $0.88 \pm 0.18$ & $0.84 \pm 0.15$ & 0.35 \\
\hline
\end{tabular}

Arterial oxygen content, $\mathrm{CaO}_{2}$; peripheral oxygen saturation, $\mathrm{SpO}_{2}$; cardiac output, $\mathrm{CO}$; heart rate, $\mathrm{HR}$; mean arterial blood pressure, $\mathrm{MABP}$; stroke volume, SV; systemic $\mathrm{O}_{2}$ delivery $=\mathrm{CO} \times \mathrm{CaO}_{2}$.

Resting BP did not differ between hypoxia and normoxia (124/76 vs. 122/74 $\mathrm{mmHg}$ $p>0.05$, respectively). Peak one-legged cycling values in normoxia and hypoxia are illustrated in Table 3. During maximal single-legged exercise, peak $\mathrm{CO}$ was higher in hypoxia compared to normoxia, mainly due to an elevated peak $\mathrm{HR}$. $\mathrm{CaO}_{2}$ was reduced at simulated altitude (lower $\mathrm{SpO}_{2}$ and $\mathrm{PaO}_{2}$ and unaffected $\mathrm{Hb}$ ). The higher $\mathrm{CO}$, despite the reduced $\mathrm{CaO}_{2}$, resulted in a higher systemic $\mathrm{O}_{2}$ delivery in hypoxia compared to normoxia. Nonetheless, peak power output $\left(p=0.03\right.$, effect size $($ Cohen's d $)=4.8$ ) and peak $\mathrm{VO}_{2}$ $(p=0.04$, effect size $($ Cohen's d $)=1.0)$ were lower in hypoxia compared to normoxia. In line with this, a- $\mathrm{vDO}_{2}$ was lower in hypoxia. Peak La concentration was higher in hypoxia compared to normoxia. Differences in peak $\mathrm{CO}$ between the normoxia and hypoxia sessions were positively correlated with differences in peak $\mathrm{VO}_{2}\left(\mathrm{r}^{2}=0.91, p<0.05\right)$ (Figure 2). 
Table 3. Peak one-legged cycling values during the normoxia and hypoxia sessions $(n=5)$.

\begin{tabular}{cccc}
\hline Variables & Normoxia & Hypoxia & $p$-Value \\
\hline $\mathrm{HR}_{\text {peak }}(\mathrm{b} / \mathrm{min})$ & $142.4 \pm 6.9$ & $155.6 \pm 3.6$ & 0.03 \\
$\mathrm{MABP}(\mathrm{mmHg})$ & $97.3 \pm 10.4$ & $99.2 \pm 14.9$ & 0.89 \\
$\mathrm{TPR}(\mathrm{mmHg} / \mathrm{L} / \mathrm{min})$ & $5.82 \pm 1.34$ & $5.21 \pm 1.71$ & 0.09 \\
$\mathrm{SV}_{\text {peak }}(\mathrm{mL})$ & $118.2 \pm 21.4$ & $121.8 \pm 23.0$ & 0.08 \\
$\mathrm{CO}_{\text {peak }}(\mathrm{L} / \mathrm{min})$ & $16.83 \pm 3.10$ & $18.96 \pm 3.59$ & 0.04 \\
$\mathrm{paO}_{2}(\mathrm{mmHg})$ & $89.4 \pm 3.2$ & $76.8 \pm 4.1$ & 0.03 \\
$\mathrm{SpO}_{2}(\%)$ & $95.9 \pm 1.8$ & $86.9 \pm 1.1$ & 0.03 \\
$\mathrm{Hb}(\mathrm{g} / \mathrm{dL})$ & $15.2 \pm 1.2$ & $15.4 \pm 1.8$ & 0.35 \\
$\mathrm{CaO}_{2}(\mathrm{~mL} / \mathrm{L})$ & $197.9 \pm 15.0$ & $181.5 \pm 19.3$ & 0.04 \\
$\mathrm{a}-\mathrm{vDO}_{2}(\mathrm{~mL} / \mathrm{L})$ & $137 \pm 21$ & $112 \pm 19$ & 0.03 \\
$\mathrm{P}_{\text {peak }}(\mathrm{W})$ & $3.37 \pm 0.84$ & $3.47 \pm 0.89$ & 0.04 \\
$\mathrm{P}_{\text {peak }}(\mathrm{W} / \mathrm{kg})$ & $154 \pm 31$ & $128 \pm 26$ & 0.03 \\
$\mathrm{VO}_{2 \text { peak }}(\mathrm{mL} / \mathrm{min})$ & $2.4 \pm 0.2$ & $2.0 \pm 0.2$ & 0.03 \\
$\mathrm{VO}_{2 \text { peak }}(\mathrm{mL} / \mathrm{min} / \mathrm{kg})$ & $2351 \pm 719$ & $2170 \pm 706$ & 0.04 \\
$\mathrm{La}_{\text {peak }}(\mathrm{mmol} / \mathrm{L})$ & $36.8 \pm 6.6$ & $33.9 \pm 6.9$ & 0.04 \\
\hline
\end{tabular}

Arterial oxygen content, $\mathrm{CaO}_{2}$ (calculated as: $\left(\mathrm{Hb} \times 1.34 \times \mathrm{SaO}_{2}\right)+\left(\mathrm{PaO}_{2} \times 0.003\right)$ ); arterial-venous $\mathrm{O}_{2}$ difference, a- $\mathrm{vDO}_{2}\left(\mathrm{CaO}_{2}-\mathrm{CvO}_{2}\right.$, calculated using the Fick equation a-vDO$\left.=\mathrm{VO}_{2} / \mathrm{CO}\right)$; hemoglobin concentration, $\mathrm{Hb}$; mean arterial blood pressure, MABP; peak cardiac output, $\mathrm{CO}_{\text {peak; }}$ peak heart rate, $\mathrm{HR}_{\text {peak }}$; peak lactate concentration, $\mathrm{La}_{\text {peak }}$; peak oxygen uptake, $\mathrm{VO}_{2 \text { peak }}$; peak power output, $\mathrm{P}_{\text {peak }}$; peak stroke volume, $\mathrm{SV}_{\text {peak }}$; peripheral oxygen saturation, $\mathrm{SpO}_{2}$; systemic $\mathrm{O}_{2}$ delivery $=\mathrm{CO} \times \mathrm{CaO}_{2}$.
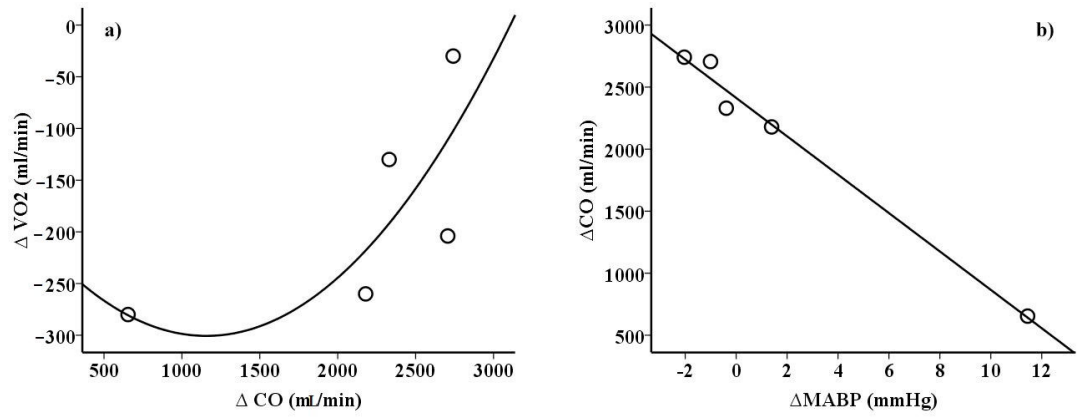

Figure 2. Relationship between changes from normoxia to hypoxia of (a) peak oxygen consumption $\left(\mathrm{VO}_{2}\right)$ and cardiac output $(\mathrm{CO})\left(\mathrm{r}^{2}=0.91\right.$, Spearman) and $(\mathbf{b}) \mathrm{CO}$ and mean arterial blood pressure (MABP) $\left(r^{2}=1.0\right.$, Spearman).

Changes (increase) of peak $\mathrm{CO}$ values from normoxia to hypoxia were negatively correlated with MABP in normoxia $\left(\mathrm{r}^{2}=0.91, p<0.05\right)$, MABP in hypoxia $\left(\mathrm{r}^{2}=0.91\right.$, $p<0.05)$, and MABP changes $\left(\mathrm{r}^{2}=1.0, p<0.05\right.$, Figure 2$)$.

\section{Discussion}

The main results of the present study show reduced peak power output $\left(\mathrm{P}_{\text {peak }}\right)$ and $\mathrm{VO}_{2 \text { peak }}$ values despite elevated systemic oxygen delivery during one-legged cycling in acute moderate hypoxia compared to normoxia. Data indicate that the $\mathrm{CO}$ increase was not sufficient to prevent the decline in $\mathrm{P}_{\text {peak }}$ and $\mathrm{VO}_{2 \text { peak }}$ in hypoxia, and that the individual magnitude of $\mathrm{VO}_{2 \text { peak }}$ reduction was closely associated with individual $\mathrm{CO}$ responses. This contrasts with our hypothesis, as we predicted unchanged one-leg performance due to compensation of the lower $\mathrm{FiO}_{2}$ and $\mathrm{SpO}_{2}$ by increased $\mathrm{CO}$, eventually supported by hemoconcentration. Since systemic $\mathrm{O}_{2}$ delivery was enhanced and $\mathrm{a}-\mathrm{vDO}_{2}$ reduced in moderate hypoxia compared to normoxia, a potential diffusion limitation cannot be excluded.

$\mathrm{P}_{\text {peak }}$ and $\mathrm{VO}_{2 \text { peak }}$ during two-legged cycling (large muscle mass involved) are primarily limited by $\mathrm{CO}$ and the associated ability to deliver $\mathrm{O}_{2}$ to the working muscles $[1,16,17]$. This, however, does not apply when exercising with a small muscle mass, i.e., one-legged cycling, because maximal CO in general is not attained [5-7]. In the present study, peak 
values of $\mathrm{CO}$ and $\mathrm{VO}_{2}$ are relatively (in proportion to the involved muscle mass) higher during cycling with one compared to two legs, i.e., $75 \%$ of two-legged $\mathrm{VO}_{2 \text { peak. }}$. Theoretically, there is still compensatory potential for $\mathrm{CO}$ to increase when oxygen delivery during cycling with one leg is affected by hypoxia, i.e., oxygen desaturation, which was actually confirmed by our findings. Why compensation is insufficient to restore performance and varies considerably between individuals remains elusive.

A novel finding of the present study, besides showing a partial compensatory increase in peak $\mathrm{CO}$ at moderate altitude, is the observation that MABP and CO changes from normoxia to hypoxia correlate closely $(\mathrm{r}=-0.91$ to -1.0$)$. Although this result appears to be influenced by a single subject displaying a large increase in MABP, it seems intriguing to speculate that baroreceptor activity might be involved in the regulation of $\mathrm{CO}$ in acute moderate hypoxia (Figure 2). Baroreflex sensitivity (hypocapnia triggered) is usually reduced in acute hypoxia, potentially related to an insufficient $\mathrm{CO}$ elevation to compensate for the hypoxia-related loss in $\mathrm{VO}_{2 \text { peak }}[18,19]$. A sufficient $\mathrm{CO}$ increase was particularly prevented in individuals with higher (but normal) values of systemic BP (and BP changes from normoxia to hypoxia), likely due to enhanced baroreceptor activity and the associated reduction in sympathetic activation and cardiac output [20]. The reduced sympathetic activation may also explain why TPR was reduced in subjects showing the highest compensatory increase in $\mathrm{CO}$. However, the fact that chemoreflex activation inhibits baroreflex activation and vice versa [21,22] complicates the interpretation of these results. Furthermore, when exercising with a small muscle mass in hypoxia (compared to normoxia), accumulation of metabolites (metaboreflex) in the contracting muscle (slightly increased La concentration in hypoxia) [23] and vascular tone regulation of the non-exercising musculature [14], influencing BP response, may interact in a complex manner. Moreover, central command, a feed-forward neural mechanism that transmits impulses to the motor neurons and in parallel modulates cardiovascular responses, may have played a role in exercise performance and $\mathrm{CO}$ adjustments [24].

In addition to $\mathrm{CO}$ limitations, muscle diffusion capacity may also affect single-leg exercise performance at altitude. We found an enhanced systemic $\mathrm{O}_{2}$ delivery and a lower $\mathrm{a}-\mathrm{vDO}_{2}$ in moderate hypoxia, which point towards impaired oxygen extraction by the working muscles. The impairment could potentially result from the lower $\mathrm{O}_{2}$ pressure gradient and/or a shortened transit time $[8,9,12]$. Increased oxygen delivery to working muscles and lower a-vDO 2 during steady-state single-leg [5,25,26], but also double-leg [10], knee-extension exercise has previously been demonstrated, albeit in more severe hypoxia than the present study. It needs to be acknowledged that in the present study, a-vDO ${ }_{2}$ was calculated and not measured, thus these data need to be interpreted with caution.

\subsection{Methodological Considerations and Limitations}

Certainly, our preliminary observation of a relationship between systemic BP and $\mathrm{CO}$ (and thus also $\mathrm{VO}_{2 \text { peak }}$ ) changes during exercise with a small muscle mass in acute moderate hypoxia must be interpreted with caution. As outlined, the relationship seems mainly driven by one subject and future studies involving a larger sample size are needed to confirm the present results. It also needs to be determined whether this relationship is valid under conditions of more severe hypoxia or when applying different exercise types. In this regard, it is important to mention that the type of exercise (e.g., one-legged dynamic knee extension vs. one-legged cycling), which also influences active muscle mass, may influence muscle blood flow and thus oxygen delivery. Consistent with this, it has been reported that the smaller the muscle mass (e.g., arms) and the less dynamic the exercise (e.g., intermittent isometric contraction), the more the muscular perfusion is impaired during maximal exercise [6,27]. The consequence is that maximal exercise is limited primarily by the intrinsic power of muscles rather than by $\mathrm{O}_{2}$ supply [6]. Since, in the present study, a one-legged cycle exercise was applied, deviating results compared with other studies may have resulted from differences in the type of exercise (e.g., knee extension). 
Sex differences in leg vasodilation during graded knee extensor exercise have been reported [28], which may have influenced the present results (males and females were included). Nonetheless, when analyzing changes from moderate altitude to sea level conditions, such differences should have little impact on the interpretation of the present data. Evidently, this only applies if there are little to no sex differences in responses to exercise in hypoxia. According to Shephard et al. [29], such differences should be minor during single-leg cycling and be most prominent when arm exercise is performed. In line with this, differences in mean $\mathrm{VO}_{2 \text { peak }}$ and $\mathrm{CO}$ between altitude and sea level were similar between males and females in the present study $(-2.9 \mathrm{~mL} / \mathrm{min} / \mathrm{kg}$ and $34.5 \mathrm{~mL} / \mathrm{min} / \mathrm{kg}$ for males and $-2.8 \mathrm{~mL} / \mathrm{min} / \mathrm{kg}$ and $33.4 \mathrm{~mL} / \mathrm{min} / \mathrm{kg}$ for females, respectively).

The main limitation, which must certainly be acknowledged and may be considered critical, is the small sample size. Nonetheless, the uniform (in every participant) increases in $\mathrm{CO}$ and reductions in $\mathrm{VO}_{2 \text { peak }}$ argue in favor of an existing compensatory increase in $\mathrm{CO}$ at moderate altitude, which was insufficient to restore normoxic $\mathrm{VO}_{2 \text { peak }}$. Furthermore, we did not monitor direct changes of cardiovascular reflexes, but the observed association between $\mathrm{MABP}, \mathrm{CO}$, and $\mathrm{VO}_{2 \text { peak }}$ suggest involvement of those reflexes, which have to be considered in future studies involving a larger sample size.

\subsection{Practical Considerations}

Peak aerobic performance when exercising/working with a small muscle mass is acutely reduced even in moderate acute hypoxia. If performance is crucial, e.g., from a safety perspective, individual values of systemic BP and training involving a small muscle mass may be considered before going to altitude [30]. Additionally, acclimatization to altitude may be of importance for workers as well as athletes who have to perform with a small muscle mass (e.g., athletes with disabilities) at moderate altitude. With prolonged altitude exposure, neural adjustments change [31], which may contribute to the restoration of normoxic small muscle exercise performance, as demonstrated at higher altitudes [1]. In addition, it has been reported that acclimatization to moderate altitude may increase left ventricular muscle mass [32,33], potentially supporting compensatory increases in CO and thus performance involving a small muscle mass. Moreover, previous studies also demonstrated improved bilateral cycling performance after one-legged cycling training in normoxia [30] and hypoxia as well [34].

\section{Conclusions}

The present study found reduced $\mathrm{P}_{\text {peak }}$ and $\mathrm{VO}_{2 \text { peak }}$, despite elevated systemic oxygen delivery, during one-legged cycling in acute, moderate $\left(\mathrm{FiO}_{2}: 15 \%\right)$ hypoxia. The related CO increase was not sufficient to prevent the decline in $\mathrm{P}_{\text {peak }}$ and $\mathrm{VO}_{2 \text { peak }}$. The magnitude of $\mathrm{VO}_{2 \text { peak }}$ reduction was associated with individual $\mathrm{CO}$ responses, which again were correlated with individual MABP values. These observations likely indicate the involvement of baroreceptor activity in the explanation of $\mathrm{CO}$ and $\mathrm{VO}_{2 \text { peak }}$ changes when exercising with a small muscle mass in acute moderate hypoxia. Not to be ignored, the enhanced systemic $\mathrm{O}_{2}$ delivery and the reduced $\mathrm{a}-\mathrm{vDO}_{2}$ in moderate hypoxia may indicate a possible diffusion limitation. These novel, yet preliminary, findings may be of clinical/practical relevance and deserve further investigation.

Author Contributions: Conceptualization, M.B., H.G. and V.M.; methodology, M.B.; investigation, M.B. and H.G.; writing-original draft preparation, H.G. and M.B.; writing—review and editing, M.B., H.G. and V.M. All authors have read and agreed to the published version of the manuscript.

Funding: This research received no external funding.

Institutional Review Board Statement: The study has been approved by the local ethics review board (University of Innsbruck, Institute of Sport Science).

Informed Consent Statement: Informed consent was obtained from all subjects involved in the study.

Data Availability Statement: Data are contained within the article. 
Acknowledgments: We thank the Department of Innovation, Research and University of the Autonomous Province of Bozen/Bolzano for covering the open access publication costs.

Conflicts of Interest: The authors declare no conflict of interest.

\section{References}

1. Calbet, J.A.; Radegran, G.; Boushel, R.; Saltin, B. On the mechanisms that limit oxygen uptake during exercise in acute and chronic hypoxia: Role of muscle mass. J. Physiol. 2009, 587, 477-490. [CrossRef] [PubMed]

2. Gatterer, H.; Greilberger, J.; Philippe, M.; Faulhaber, M.; Djukic, R.; Burtscher, M. Short-Term Supplementation with AlphaKetoglutaric Acid and 5-Hydroxymethylfurfural Does not Prevent the Hypoxia Induced Decrease of Exercise Performance Despite Attenuation of Oxidative Stress. Int. J. Sports Med. 2013, 34, 1-7. [CrossRef] [PubMed]

3. Treml, B.; Gatterer, H.; Burtscher, J.; Kleinsasser, A.; Burtscher, M. A Focused Review on the Maximal Exercise Responses in Hypoand Normobaric Hypoxia: Divergent Oxygen Uptake and Ventilation Responses. Int. J. Environ. Res. Public Health 2020, 17, 5239. [CrossRef] [PubMed]

4. $\quad$ Burtscher, M.; Gatterer, H.; Burtscher, J.; Mairbaurl, H. Extreme Terrestrial Environments: Life in Thermal Stress and Hypoxia. A Narrative Review. Front. Physiol. 2018, 9, 572. [CrossRef]

5. Rowell, L.B.; Saltin, B.; Kiens, B.; Christensen, N.J. Is peak quadriceps blood flow in humans even higher during exercise with hypoxemia? Am. J. Physiol. 1986, 251, H1038-H1044. [CrossRef]

6. Shephard, R.J.; Bouhlel, E.; Vandewalle, H.; Monod, H. Muscle mass as a factor limiting physical work. J. Appl. Physiol. 1988, 64, 1472-1479. [CrossRef]

7. Roach, R.C.; Koskolou, M.D.; Calbet, J.A.; Saltin, B. Arterial O2 content and tension in regulation of cardiac output and leg blood flow during exercise in humans. Am. J. Physiol. 1999, 276, H438-H445. [CrossRef]

8. Hogan, M.C.; Roca, J.; Wagner, P.D.; West, J.B. Limitation of maximal O2 uptake and performance by acute hypoxia in dog muscle in situ. J. Appl. Physiol. 1988, 65, 815-821. [CrossRef]

9. Richardson, R.S.; Knight, D.R.; Poole, D.C.; Kurdak, S.S.; Hogan, M.C.; Grassi, B.; Wagner, P.D. Determinants of maximal exercise VO2 during single leg knee-extensor exercise in humans. Am. J. Physiol. 1995, 268, H1453-H1461. [CrossRef]

10. Koskolou, M.D.; Calbet, J.A.; Rådegran, G.; Roach, R.C. Hypoxia and the cardiovascular response to dynamic knee-extensor exercise. Am. J. Physiol. 1997, 272, H2655-H2663. [CrossRef]

11. Richardson, R.S.; Grassi, B.; Gavin, T.P.; Haseler, L.J.; Tagore, K.; Roca, J.; Wagner, P.D. Evidence of O2 supply-dependent VO2 max in the exercise-trained human quadriceps. J. Appl. Physiol. 1999, 86, 1048-1053. [CrossRef]

12. Wagner, P.D. New ideas on limitations to VO2max. Exerc. Sport Sci. Rev. 2000, 28, 10-14.

13. Saltin, B.; Calbet, J.A. Point: In health and in a normoxic environment, VO2 max is limited primarily by cardiac output and locomotor muscle blood flow. J. Appl. Physiol. 2006, 100, 744-745. [CrossRef]

14. Casey, D.P.; Joyner, M.J. Compensatory vasodilatation during hypoxic exercise: Mechanisms responsible for matching oxygen supply to demand. J. Physiol. 2012, 590, 6321-6326. [CrossRef]

15. Siebenmann, C.; Rasmussen, P.; Sorensen, H.; Zaar, M.; Hvidtfeldt, M.; Pichon, A.; Secher, N.H.; Lundby, C. Cardiac output during exercise: A comparison of four methods. Scand. J. Med. Sci. Sports 2015, 25, e20-e27. [CrossRef]

16. Naeije, R. Physiological adaptation of the cardiovascular system to high altitude. Prog. Cardiovasc. Dis. 2010, 52, 456-466. [CrossRef]

17. Faoro, V.; Deboeck, G.; Vicenzi, M.; Gaston, A.F.; Simaga, B.; Doucende, G.; Hapkova, I.; Roca, E.; Subirats, E.; Durand, F.; et al. Pulmonary Vascular Function and Aerobic Exercise Capacity at Moderate Altitude. Med. Sci. Sports Exerc. 2017, 49, 2131-2138. [CrossRef]

18. Bourdillon, N.; Yazdani, S.; Subudhi, A.W.; Lovering, A.T.; Roach, R.C.; Vesin, J.M.; Kayser, B. AltitudeOmics: Baroreflex Sensitivity During Acclimatization to 5260 m. Front. Physiol. 2018, 9, 767. [CrossRef]

19. Beltrán, A.R.; Arce-Álvarez, A.; Ramirez-Campillo, R.; Vásquez-Muñoz, M.; von Igel, M.; Ramírez, M.A.; Del Rio, R.; Andrade, D.C. Baroreflex Modulation During Acute High-Altitude Exposure in Rats. Front. Physiol. 2020, 11, 1049. [CrossRef]

20. Bernardi, L. Heart rate and cardiovascular variability at high altitude. In Proceedings of the 2007 29th Annual International Conference of the IEEE Engineering in Medicine and Biology Society, Lyon, France, 22-26 August 2007; pp. 6679-6681. [CrossRef]

21. Somers, V.K.; Mark, A.L.; Abboud, F.M. Interaction of baroreceptor and chemoreceptor reflex control of sympathetic nerve activity in normal humans. J. Clin. Investig. 1991, 87, 1953-1957. [CrossRef]

22. Cooper, V.L.; Pearson, S.B.; Bowker, C.M.; Elliott, M.W.; Hainsworth, R. Interaction of chemoreceptor and baroreceptor reflexes by hypoxia and hypercapnia-a mechanism for promoting hypertension in obstructive sleep apnoea. J. Physiol. 2005, 568, 677-687. [CrossRef] [PubMed]

23. Mortensen, S.P.; Svendsen, J.H.; Ersboll, M.; Hellsten, Y.; Secher, N.H.; Saltin, B. Skeletal muscle signaling and the heart rate and blood pressure response to exercise: Insight from heart rate pacing during exercise with a trained and a deconditioned muscle group. Hypertension 2013, 61, 1126-1133. [CrossRef] [PubMed]

24. Murphy, M.N.; Mizuno, M.; Mitchell, J.H.; Smith, S.A. Cardiovascular regulation by skeletal muscle reflexes in health and disease. Am. J. Physiol. Heart Circ. Physiol. 2011, 301, H1191-H1204. [CrossRef] [PubMed] 
25. Heinonen, I.H.; Kemppainen, J.; Kaskinoro, K.; Peltonen, J.E.; Borra, R.; Lindroos, M.; Oikonen, V.; Nuutila, P.; Knuuti, J.; Boushel, R.; et al. Regulation of human skeletal muscle perfusion and its heterogeneity during exercise in moderate hypoxia. Am. J. Physiol. 2010, 299, R72-R79. [CrossRef] [PubMed]

26. DeLorey, D.S.; Shaw, C.N.; Shoemaker, J.K.; Kowalchuk, J.M.; Paterson, D.H. The effect of hypoxia on pulmonary O2 uptake, leg blood flow and muscle deoxygenation during single-leg knee-extension exercise. Exp. Physiol. 2004, 89, 293-302. [CrossRef]

27. Laaksonen, M.S.; Kalliokoski, K.K.; Kyrolainen, H.; Kemppainen, J.; Teras, M.; Sipila, H.; Nuutila, P.; Knuuti, J. Skeletal muscle blood flow and flow heterogeneity during dynamic and isometric exercise in humans. Am. J. Physiol. Heart Circ. Physiol. 2003, 284, H979-H986. [CrossRef]

28. Parker, B.A.; Smithmyer, S.L.; Pelberg, J.A.; Mishkin, A.D.; Herr, M.D.; Proctor, D.N. Sex differences in leg vasodilation during graded knee extensor exercise in young adults. J. Appl. Physiol. 2007, 103, 1583-1591. [CrossRef]

29. Shephard, R.J.; Vandewalle, H.; Bouhlel, E.; Monod, H. Sex differences of physical working capacity in normoxia and hypoxia. Ergonomics 1988, 31, 1177-1192. [CrossRef]

30. Abbiss, C.R.; Karagounis, L.G.; Laursen, P.B.; Peiffer, J.J.; Martin, D.T.; Hawley, J.A.; Fatehee, N.N.; Martin, J.C. Single-leg cycle training is superior to double-leg cycling in improving the oxidative potential and metabolic profile of trained skeletal muscle. J. Appl. Physiol. 2011, 110, 1248-1255. [CrossRef]

31. Simpson, L.L.; Steinback, C.D.; Stembridge, M.; Moore, J.P. A sympathetic view of blood pressure control at high altitude: New insights from microneurographic studies. Exp. Physiol. 2020, 106, 377-384. [CrossRef]

32. Polizzi, G.; Giaccone, M.; Gervasi, M.; D’Amato, A.; Palma, A.; Bartolucci, C.; Brandoni, G.; Federici, A.; Lucertini, F. Pilot study on cardiac and metabolic responses to moderate-altitude endurance training in middle-distance runners. Med. Sport 2014, 67, 633-641.

33. Svedenhag, J.; Piehl-Aulin, K.; Skog, C.; Saltin, B. Increased left ventricular muscle mass after long-term altitude training in athletes. Acta Physiol. Scand. 1997, 161, 63-70. [CrossRef]

34. Menz, V.; Semsch, M.; Mosbach, F.; Burtscher, M. Cardiorespiratory Effects of One-Legged High-Intensity Interval Training in Normoxia and Hypoxia: A Pilot Study. J. Sports Sci. Med. 2016, 15, 208-213. 